\title{
Merging 3D optical measurement system (structured light-based surface topography) and digital radiograms - the technique and preliminary results
}

\author{
Glinkowski Wojciech*, Paśko Sławomir, Walesiak Katarzyna, Sitnik Robert, Górecki Andrzej
}

From 10th International Conference on Conservative Management of Spinal Deformities - SOSORT 2013

Annual Meeting

Chicago, IL, USA. 8-11 May 2013

\section{Background}

Diagnosing scoliosis requires the ability to visualize curvature of the spine in a 3-dimensional (3D) environment. 2-dimensional $\mathrm{X}$ ray remains the primary imaging modality [1]. However, recent progress in 3D-optical imaging may improve diagnostics and increase its safety for scoliosis patients [2].

\section{Purpose}

The purpose of this study was to present the potential usefulness of merging data from the 1-directional radiogram with a 3D model obtained with an optical measurement system.

\section{Methods}

The images of 11 adolescents (average age 15.05 years) with adolescent idiopathic scoliosis (AIS) were selected for this study. Average Cobb angle $31.7^{\circ}$ surface kyphosis angle $10.45^{\circ}$ and surface lordosis angle $36.06^{\circ}$. An IRB was approved for this study. The merging algorithms were developed as an operational plug-in for OsiriX Imaging Software used in the facility for viewing medical images from the hospital PACS system. The 3D data from a 4-directional $\left(360^{\circ}\right) 3 \mathrm{D}$ optical measurement system (structured light-based surface topography) and digital radiograms were merged into one, consistent 3D model. The plug-in allowed loading and adjusting the data collected by these two systems. Finally, the

\footnotetext{
* Correspondence: w.glinkowski@gmail.com

Chair and Department of Orthopaedics and Traumatology of Locomotor System, Center of Excellence "TeleOrto", Baby Jesus Clinical Hospital, Medical University of Warsaw, Poland
}

composed 3D image was viewed, processed and saved in DICOM file format.

\section{Results}

Merged images showed the data obtained from a 4-directional 3D optical system and $X$ ray for the same patient made the same day. The results of this comparison are presented in graphical form. Additionally, patients appreciated that the merged $3 \mathrm{D} / \mathrm{X}$ ray images provided a better understanding of the deformity and the ability to see their body surface from a new, unexpected perspective.

\section{Conclusions and discussion}

Merging of data obtained with the 4-directional optical measurement system with data taken from another medical system, such as $\mathrm{X}$ ray photography, gives physicians a powerful diagnostics tool that, combines the advantages of both examination methods [3]. Moreover, as acquisition time for 4-directional optical measurement is short (a few seconds) and there is no $\mathrm{X}$ ray radiation, the examination can be repeated as many times as needed.

\section{Acknowledgement \\ This project NR13-0109-10/2010 is founded by National Center for Research and Development. \\ Published: 18 September 2013 \\ References \\ 1. Kotwicki T: Evaluation of scoliosis today: examination, X-rays and beyond. Disabil Rehabil 2008, 30(10):742-751.}

\section{C)


2. Michonski J, Glinkowski W, Witkowski M, Sitnik R: Automatic recognition of surface landmarks of anatomical structures of back and posture. J Biomed Opt 2012, 17(5):056015.

3. Chen YT, Wang MS: Three-dimensional reconstruction and fusion for multi-modality spinal images. Comput Med Imaging Graph 2004, 28(1-2):21-31.

doi:10.1186/1748-7161-8-S2-O24

Cite this article as: Wojciech et al: Merging 3D optical measurement system (structured light-based surface topography) and digital radiograms - the technique and preliminary results. Scoliosis 20138 (Suppl 2):O24.

Submit your next manuscript to BioMed Central and take full advantage of:

- Convenient online submission

- Thorough peer review

- No space constraints or color figure charges

- Immediate publication on acceptance

- Inclusion in PubMed, CAS, Scopus and Google Scholar

- Research which is freely available for redistribution

Submit your manuscript at www.biomedcentral.com/submit
C Biomed Central 